\title{
Saddle-shaped tetraphenylenes with peripheral gallic esters displaying columnar mesophases
}

\author{
Eugen Wuckert ${ }^{1}$, Constanze Hägele ${ }^{2}$, Frank Giesselmann ${ }^{2}$, Angelika Baro ${ }^{1}$ \\ and Sabine Laschat ${ }^{* 1}$
}

\section{Full Research Paper}

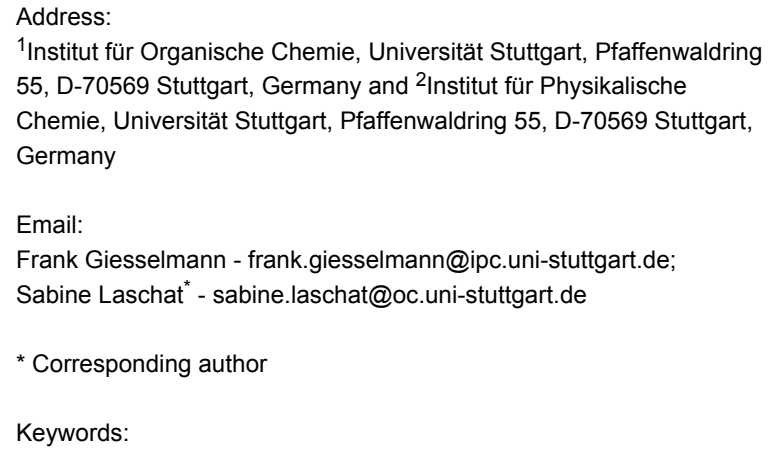

Beilstein Journal of Organic Chemistry 2009, 5, No. 57. doi:10.3762/bjoc. 5.57

Received: 31 July 2009

Accepted: 08 October 2009

Published: 21 October 2009

Guest Editor: S. Laschat

(c) 2009 Wuckert et al; licensee Beilstein-Institut. License and terms: see end of document.

\begin{abstract}
Tetraphenylenes 2 with eight peripheral gallic esters were prepared in two steps from octamethoxytetraphenylene 1 in 19-72\% yield. Investigation of the mesomorphic properties of $\mathbf{2}$ by DSC, POM and X-ray diffraction revealed that derivatives $\mathbf{2 a - d}$ with short alkoxy chain lengths $\left(\mathrm{C}_{5}-\mathrm{C}_{8}\right)$ did not show any mesomorphic properties, whereas compounds $2 \mathbf{e}-\mathbf{i}$ with $\mathrm{C}_{9}-\mathrm{C}_{13}$ chains displayed rectangular columnar mesophases and compounds $\mathbf{2} \mathbf{j}-\mathbf{l}$ with $\mathrm{C}_{14}-\mathrm{C}_{16}$ chains displayed hexagonal columnar mesophases. Furthermore an anomalous odd-even effect of the clearing points of compounds $\mathbf{2 e - 1}$ versus chain length was detected.
\end{abstract}

\section{Introduction}

Columnar liquid crystals have received increasing interest during the last decade due to their 1D charge transport and selfhealing properties, which make them particularly promising candidates for organic field effect transistors, organic photovoltaic devices and light emitting diodes [1-3]. Tetraphenylenes, whose saddle-shaped conformation is caused by the antiaromatic character of the corresponding central flat 8-membered ring [4-6], are suitable building blocks for supramolecular chemistry, asymmetric catalysis and formation of inclusion complexes [3-28]. We have shown that tetraphenylenes with eight peripheral alkoxy or alkanoate chains display thermo- tropic columnar and smectic mesophases [29,30]. Furthermore, anomalous odd-even effects were discovered for these discotic tetraphenylenes, i.e. the ascending and descending transition temperatures with increasing numbers of methylene groups in the side chain exhibit an inversion of this alternation between $n=12$ and $n=14$ homologues [31]. In order to explore whether this anomalous odd-even effect is a more general phenomenon, the corresponding gallic ester-substituted tetraphenylenes were prepared and their liquid crystalline properties were investigated. In addition, we were curious about the mesophase types, because tetraphenylenes with peripheral alkoxy or alkanoate 
chains displayed smectic mesophases in addition to columnar phases, whereas the corresponding tetraphenylenes with $p$-alkoxybenzoate substituents displayed only columnar mesophases even with long chain lengths [29-31]. Thus, we anticipated that the presence of the sterically demanding gallic esters in the periphery of the tetraphenylene can be accommodated much better by columnar packing as compared to a smectic layer structure. The results are discussed below.

\section{Results and Discussion}

The synthesis started from the known octamethoxytetraphenylene 1 [4,19,20,29-31], which was demethylated with boron tribromide in $\mathrm{CH}_{2} \mathrm{Cl}_{2}$ at $-50{ }^{\circ} \mathrm{C}$ to room temp. followed by hydrolysis with $\mathrm{MeOH}$ (Scheme 1). Subsequent treatment with gallic acid chlorides in the presence of catalytic amounts of DMAP in pyridine/ $\mathrm{CH}_{2} \mathrm{Cl}_{2}$ yielded after aqueous workup and

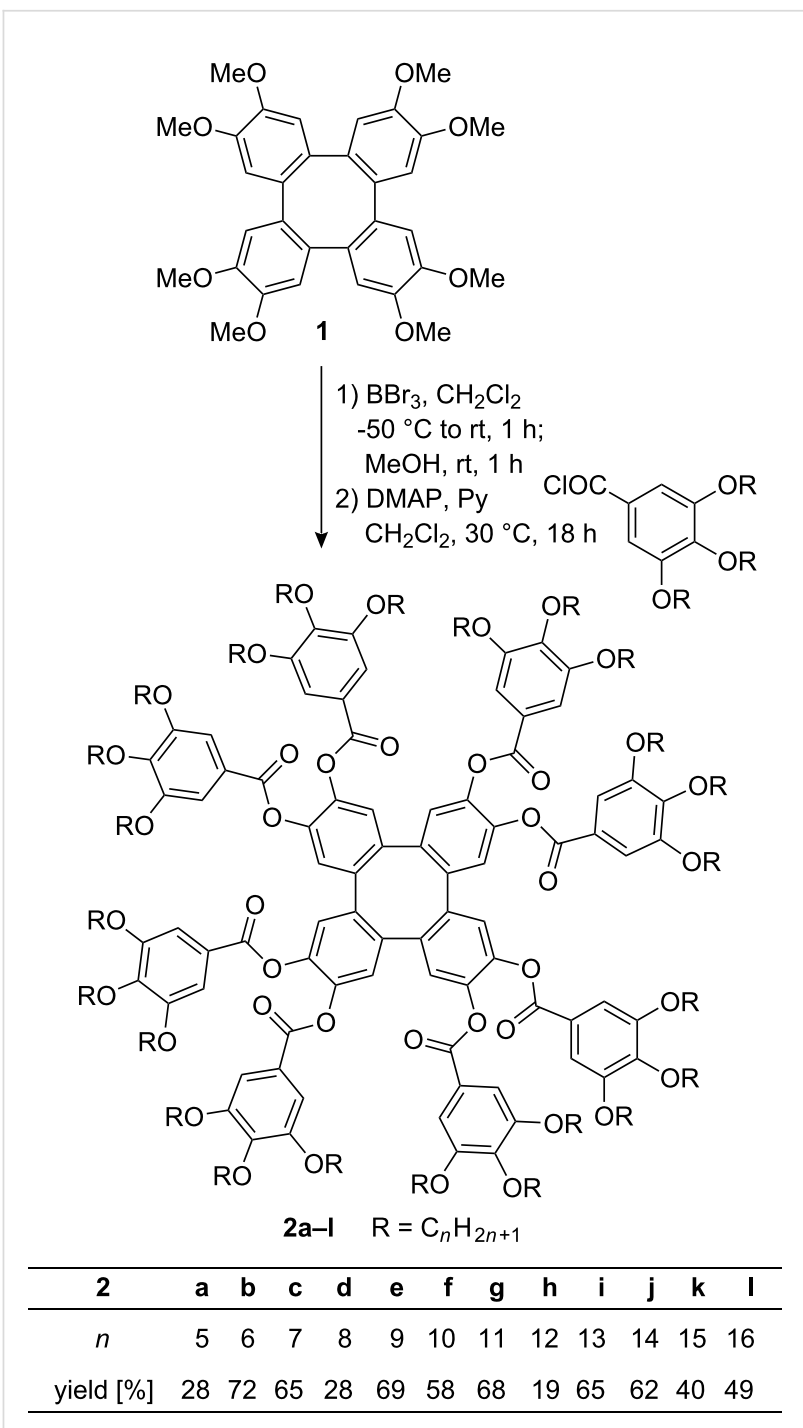

Scheme 1: Synthesis of tetraphenylenes 2. chromatographic purification the desired gallic ester-substituted tetraphenylenes $\mathbf{2 a}-\mathbf{l}$ in $19-72 \%$. In some cases purification turned out to be rather tedious resulting in decreased yields.

Mesomorphic properties of compounds 2 were studied by differential scanning calorimetry (DSC), polarizing optical microscopy (POM) and X-ray diffraction (WAXS, SAXS). The DSC results are summarized in Table 1.

While compounds $\mathbf{2 a}-\mathbf{d}$ with chain lengths up to $\mathrm{C}_{8}$ showed only crystal to crystal transitions and isotropic melting, tetraphenylenes $\mathbf{2 e}-\mathbf{l}$ with chain lengths between $\mathrm{C}_{9}$ and $\mathrm{C}_{16}$ displayed enantiotropic mesomorphism. For compounds $\mathbf{2 e , f}$ additional crystal to crystal transitions were detected. A typical DSC curve is shown in Figure 1. Thus tetraphenylene $\mathbf{2 h}$ with dodecyl chains displays a melting transition at $3{ }^{\circ} \mathrm{C}$ and a clearing transition at $36^{\circ} \mathrm{C}$ upon second heating. Upon cooling an isotropic to mesophase transition at $33{ }^{\circ} \mathrm{C}$ and a crystallization peak at $0{ }^{\circ} \mathrm{C}$ were detected. The hysteresis phenomena observed for some compounds are probably due to supercooling, which is common for such highly viscous materials.

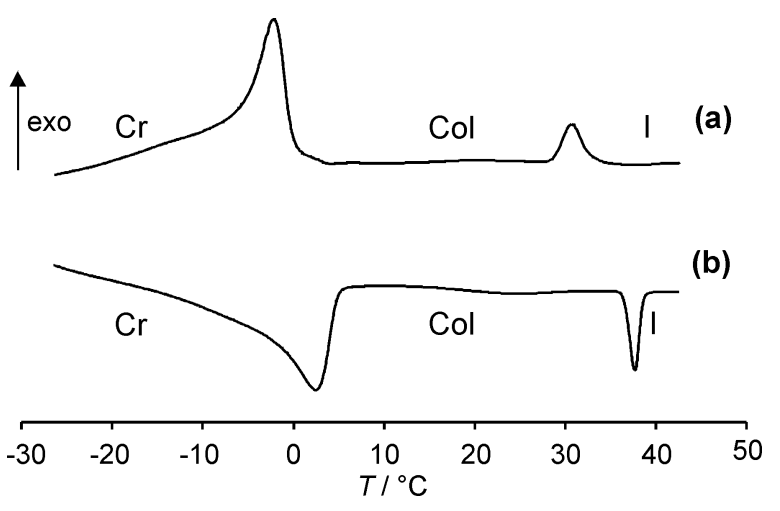

Figure 1: DSC traces of compound $\mathbf{2 h}$ during (a) second cooling and (b) second heating (heating/cooling rate $5 \mathrm{~K} / \mathrm{min}$ ).

POM investigations revealed focal conic and fan-shaped textures typical for columnar mesophases (Figure 2).

However, clear evidence was possible only by XRD data, which are summarized in Table 2. While rectangular columnar mesophases were observed for tetraphenylenes $\mathbf{2 e - i}$ with shorter chains $(n=9-13)$ (shown for $2 \mathbf{f}$ in Figure S1 in the Supporting Information), hexagonal columnar mesophases were found for the long chain derivatives $\mathbf{2} \mathbf{j}-\mathbf{l}(n=14-16)$ (shown for $\mathbf{2} \mathbf{j}$ in Figure S2 in the Supporting Information). Indeed, as expected the columnar mesophase seems to accommodate the eight bulky gallic esters much better than the smectic layer structure. 


\begin{tabular}{|c|c|c|c|c|c|c|c|c|c|c|c|}
\hline 2 & $n$ & $\mathrm{Cr}_{1}$ & & $\mathrm{Cr}_{2}$ & & $\mathrm{Cr}_{3}$ & & Col & & I & \\
\hline $\mathbf{a}$ & 5 & • & $51(10.1)$ & - & $79(4.4)$ & • & $191(15.3)$ & -- & & • & 2. heating \\
\hline b & 6 & $\cdot$ & $46(8.3)$ & • & $69(7.4)$ & - & $142(11.2)$ & -- & & • & 2. heating \\
\hline c & 7 & • & $10(1.7)$ & - & $41(0.6)$ & - & $55(0.6)$ & -- & & - & 2. heating \\
\hline d & 8 & • & $4(15.0)$ & - & $41(27.7)$ & - & $62(7.2)$ & -- & & - & 2. heating \\
\hline e & 9 & $\cdot$ & $-6(11.6)$ & • & $35(4.2)$ & -- & & $\cdot$ & $37(3.8)$ & $\cdot$ & 2. heating \\
\hline e & 9 & • & $1(-2.7)$ & - & $11(-0.8)$ & -- & & $\cdot$ & $26(-5.3)$ & - & 2. cooling \\
\hline$f$ & 10 & • & $7(4.1)$ & • & $40(12.5)$ & -- & & - & $46(5.6)$ & • & 2. heating \\
\hline$f$ & 10 & • & $24(-7.9)$ & -- & & -- & & • & $39(-5.7)$ & • & 2. cooling \\
\hline g & 11 & • & $29(7.4)$ & -- & & -- & & - & $43(1.0)$ & • & 2. heating \\
\hline g & 11 & • & $20(-7.6)$ & -- & & -- & & - & $40(-1.1)$ & - & 2. cooling \\
\hline h & 12 & • & $3(19.4)$ & -- & & -- & & - & $36(10.3)$ & • & 2. heating \\
\hline $\mathbf{h}$ & 12 & $\cdot$ & $0(-18.6)$ & -- & & -- & & • & $33(-9.7)$ & - & 2. cooling \\
\hline $\mathbf{i}$ & 13 & $\cdot$ & $16(18.5)$ & -- & & -- & & - & $33(11.9)$ & - & 2. heating \\
\hline i & 13 & • & $13(-18.9)$ & -- & & -- & & - & $28(-13.4)$ & - & 2. cooling \\
\hline $\mathbf{j}$ & 14 & • & $16(9.6)$ & -- & & -- & & • & $41(2.5)$ & - & 2. heating \\
\hline j & 14 & $\cdot$ & $16(-5.8)$ & -- & & -- & & • & $29(-1.8)$ & - & 2. cooling \\
\hline k & 15 & • & $25(8.0)$ & -- & & -- & & - & $36(20.1)$ & - & 2. heating \\
\hline k & 15 & • & $20(-10.3)$ & -- & & -- & & - & $32(-16.2)$ & • & 2. cooling \\
\hline 1 & 16 & -- & & -- & & -- & & • & $41(36.2)$ & - & 2. heating \\
\hline I & 16 & • & $22(-5.2)$ & -- & & -- & & - & $36(-17.3)$ & - & 2. cooling \\
\hline
\end{tabular}

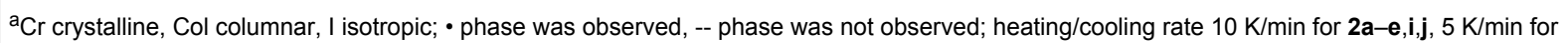

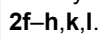

The crossover from rectangular columnar to hexagonal columnar mesophases with increasing chain lengths has been also observed in other columnar systems [32,33] and has been attributed to the enhanced core-core interaction necessary for the formation of the $\mathrm{Col}_{\mathrm{r}}$ phases [34]. According to molecular modelling [35] and comparison with the XRD data each disk within the hexagonal and rectangular columnar pattern is occu-

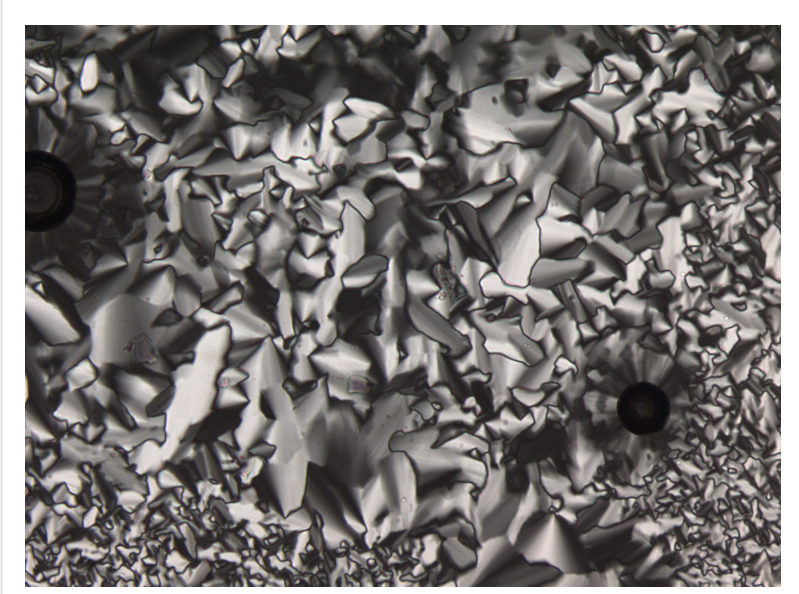

Figure 2: Texture of $\mathbf{2 h}$ under the $\mathrm{POM}$ at $25^{\circ} \mathrm{C}$ upon cooling from the isotropic liquid (heating/cooling rate $5 \mathrm{~K} / \mathrm{min}$; magnification $100 \times$ ). pied by one tetraphenylene molecule. For better visibility only the modelled tetraphenylene (octakis)acyl core unit is shown in Figure 3, which reveals the saddle shape.

Next, the clearing points of mesogenic compounds $2 \mathbf{e}-\mathbf{l}$ were plotted against the chain lengths $n$ (Figure 4). An anomalous odd-even effect can be seen, which inverts at $n=11$.

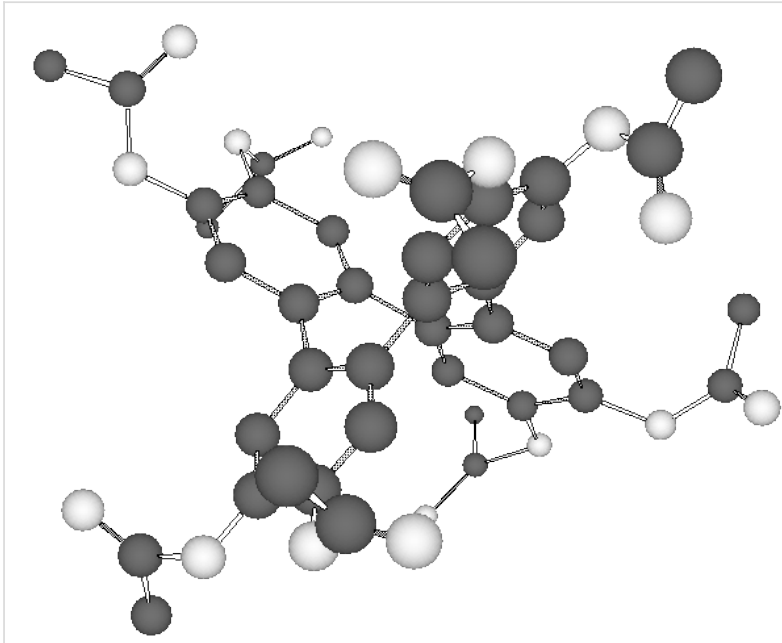

Figure 3: Molecular modelling of the saddle-shaped tetraphenylene (octakis)acyl core unit of 2 [35]. 


\begin{tabular}{|c|c|c|c|c|c|c|}
\hline 2 & $T\left[{ }^{\circ} \mathrm{C}\right]$ & $\theta\left[^{\circ}\right]$ & $\left.d_{\text {obs }}[\AA]\right]$ & $h k$ & $d_{\text {calc }}[\AA]$ & Mesophase parameters \\
\hline \multirow[t]{3}{*}{$2 e$} & 20 & 1.71 & 25.9 & (20) & 25.9 & $\mathrm{Col}_{\mathrm{r}}$ \\
\hline & & 2.93 & 15.1 & $(11)$ & 15.1 & $a=51.8 \AA$ \\
\hline & & 3.33 & 13.3 & $(21)$ & 13.5 & $b=15.8 \AA$ \\
\hline \multirow[t]{3}{*}{$2 f$} & 32 & 1.73 & 25.6 & $(20)$ & 18.4 & $\mathrm{Col}_{\mathrm{r}}$ \\
\hline & & 2.32 & 19.0 & $(11)$ & 19.0 & $a=51.2 \AA$ \\
\hline & & 3.34 & 13.2 & (31) & 13.1 & $b=20.5 \AA$ \\
\hline \multirow[t]{3}{*}{$2 g$} & 15 & 1.60 & 27.7 & $(20)$ & 27.7 & $\mathrm{Col}_{\mathrm{r}}$ \\
\hline & & 2.17 & 20.4 & (11) & 20.4 & $a=55.4 \AA$ \\
\hline & & 3.14 & 14.1 & (31) & 14.1 & $b=21.9 \AA$ \\
\hline \multirow[t]{3}{*}{$2 \mathrm{~h}$} & 20 & 1.51 & 29.3 & $(20)$ & 29.3 & $\mathrm{Col}_{\mathrm{r}}$ \\
\hline & & 2.25 & 19.6 & (11) & 19.6 & $a=58.6 \AA$ \\
\hline & & & & & & $b=20.8 \AA$ \\
\hline \multirow[t]{3}{*}{$2 \mathbf{i}$} & 25 & 1.47 & 30.1 & $(20)$ & 30.1 & $\mathrm{Col}_{\mathrm{r}}$ \\
\hline & & 2.28 & 19.4 & (11) & 19.4 & $a=60.3 \AA$ \\
\hline & & & & & & $b=20.5 \AA$ \\
\hline \multirow[t]{2}{*}{$2 \mathrm{j}$} & 30 & 1.46 & 30.3 & (10) & 30.6 & $\mathrm{Col}_{\mathrm{h}}$ \\
\hline & & 2.47 & 17.9 & (11) & 17.7 & $a=35.3 \AA$ \\
\hline \multirow[t]{4}{*}{$2 k$} & 20 & 1.40 & 31.6 & (10) & 31.9 & Coln $_{h}$ \\
\hline & & 2.39 & 18.5 & (11) & 18.4 & $a=36.9 \AA$ \\
\hline & & 2.75 & 16.1 & $(20)$ & 16.0 & \\
\hline & & 3.65 & 12.1 & (21) & 12.1 & \\
\hline \multirow[t]{3}{*}{21} & 20 & 1.35 & 32.8 & (10) & 33.1 & $\mathrm{Col}_{\mathrm{h}}$ \\
\hline & & 2.32 & 19.0 & (11) & 19.1 & $a=38.2 \AA$ \\
\hline & & 3.50 & 12.6 & (21) & 12.5 & \\
\hline
\end{tabular}

aDiffraction angle $\theta$; observed and calculated diffraction spacings $d_{\mathrm{obs}}$ and $d_{\text {calc; }}$; Miller indices $h k$.

For the previously studied tetraphenylene derivatives with alkoxy, alkanoate and $p$-alkoxybenzoate chains the inversion was observed at $n=12-13$ [31]. Although in all four cases an anomalous odd-even effect is present, the chain length dependence of the clearing temperatures differs somewhat. For derivatives with alkoxy or alkanoate chains directly attached to the tetraphenylene unit, the oxygen atom is part of the chain and thus odd carbon chains are actually even-numbered. They

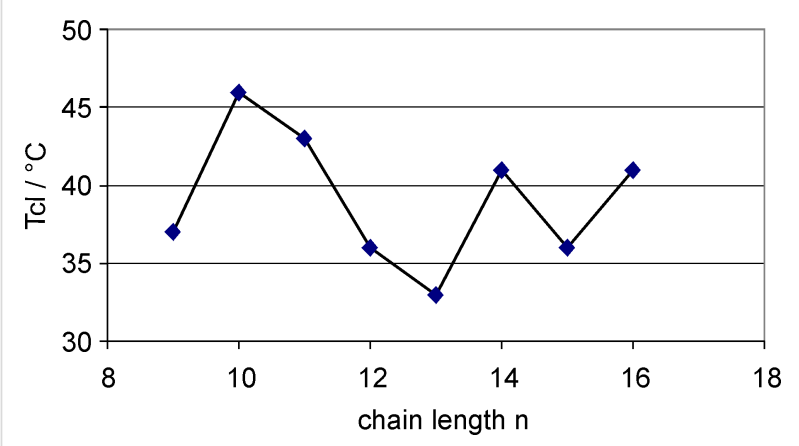

Figure 4: Clearing temperatures $T_{\mathrm{Cl}}\left[{ }^{\circ} \mathrm{C}\right]$ of tetraphenylenes $2 \mathrm{e}-\mathrm{I}$ as a function of the chain lengths $n$. should thus have an elongated shape which should lead to a higher degree of orientational order and hence a higher clearing temperature than the odd-numbered chains (including oxygen), i.e. those with an even-number of carbon atoms. The data in Figure 4 suggest that for 3,4,5-trialkoxygallic esters 2 this argument does not hold and the orientational order and hence the clearing temperature is determined both by the alkoxy chain lengths as well as the rigid gallic acid moiety. In order to eliminate the influence of the alkyl side chain on the odd-even effect of the tetraphenylenes the melting temperatures $T_{\mathrm{m}}{ }^{\text {alk }}$ of $n$-alkanes were subtracted from the clearing points $T_{\mathrm{cl}}$ of the respective tetraphenylenes 2 (Figure 5). An almost regular effect could be seen. Thus it seems that transition temperatures are also governed by the influence of the gallic ester moiety on the dynamic properties of the alkyl tails.

\section{Conclusion}

In conclusion, only columnar mesophases have been found for gallic ester-substituted tetraphenylenes $\mathbf{2 e - 1}$ with a minimum chain length of $n=9$. An anomalous odd-even effect was detected, in which the alternation of the melting transition inverses at $n=11$. The results agree with previous findings, and 


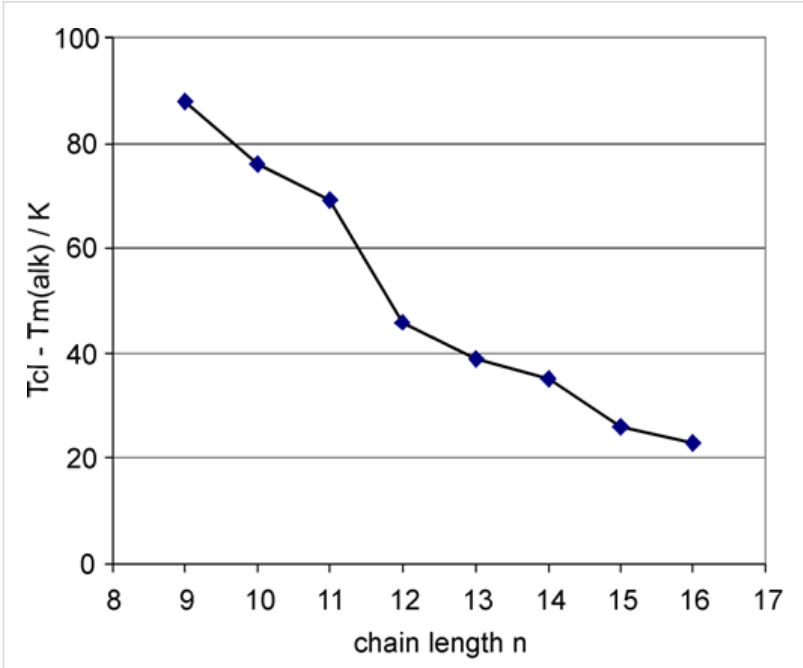

Figure 5: The differences between the clearing temperatures $T_{\mathrm{Cl}}\left[{ }^{\circ} \mathrm{C}\right]$ of tetraphenylenes 2 and the melting points $T_{\mathrm{m}}$ alk of the $n$-alkanes exhibit an almost normal odd-even effect without any inversion of the alteration.

suggest that the anomalous odd-even effect is a more general phenomenon than previously thought. Investigations to extend this concept to other classes of liquid crystals are currently in progress.

\section{Experimental General}

Melting points were measured on a Mettler Toledo DSC822 and are uncorrected. NMR spectra were recorded on a Bruker Avance 300 and Avance 500 spectrometer. FT-IR spectra were recorded on a Bruker Vektor22 spectrometer with MKII Golden Gate Single Reflection Diamant ATR system. Mass spectra were recorded on a Finnigan MAT 95 and a Varian MAT 711 apparatus. Small-angle scattering data from unaligned samples (filled into Mark capillary tubes of $0.7 \mathrm{~mm}$ diameter) were obtained using a Kratky compact camera (A. Paar) provided with a temperature controller (A. Paar) and a one-dimensional electronic detector (M. Braun). Aligned samples were exposed in a home-made flat-film camera and the 2D diffraction patterns recorded with an imaging plate detector (Fuji BAS SR). In the flat-film camera, the sample was placed in a small hole of a brass block, the temperature of which was controlled by a Lakeshore controller and kept in a $1.5 \mathrm{~T}$ magnetic field for alignment.

Differential scanning calorimetry (DSC) was performed using a Mettler Toledo DSC822, and polarizing optical microscopy (POM) using an Olympus BX50 polarizing microscope combined with a Linkam LTS350 hot stage and a Linkam TP93 central processor. Flash chromatography was performed using Kieselgel 60, 40-63 $\mu \mathrm{m}$ (Fluka). All solvents were dried, and reactions were performed in dried glassware. The used petroleum ether (PE) had a boiling range of $30-75^{\circ} \mathrm{C}$. Octamethoxytetraphenylene 1 was prepared as described in ref. [31].

\section{General procedure for the preparation of heptakis[(3,4,5-trialkoxybenzoyl)oxy]tetra- phenylen-2-yl 3,4,5-trialkoxybenzoates (2)}

To a solution of octamethoxytetraphenylene $1(0.14 \mathrm{~g}, 0.25$ $\mathrm{mmol})$ in $\mathrm{CH}_{2} \mathrm{Cl}_{2}(2 \mathrm{~mL})$ were added $\mathrm{BBr}_{3}(2.2 \mathrm{~mL}, 2.2 \mathrm{mmol}$, $1 \mathrm{M}$ solution in $\mathrm{CH}_{2} \mathrm{Cl}_{2}$ ) at $-50{ }^{\circ} \mathrm{C}$ and the mixture was stirred for $1 \mathrm{~h}$ at room temp. The solvent was removed in vacuo and the residue was dissolved in degassed $\mathrm{MeOH}(5 \mathrm{~mL})$ for $1 \mathrm{~h}$ and evaporated. The residue was dissolved in $\mathrm{CH}_{2} \mathrm{Cl}_{2}(2 \mathrm{~mL})$, treated with DMAP $(4 \mathrm{mg}, 0.03 \mathrm{mmol})$ and pyridine $(1 \mathrm{~mL})$ and gallic acid chloride $(5 \mathrm{mmol})$ were added dropwise. After stirring overnight at $30{ }^{\circ} \mathrm{C}$, the mixture was diluted with $\mathrm{CH}_{2} \mathrm{Cl}_{2}$ $(10 \mathrm{~mL})$, hydrolyzed with $2 \mathrm{M} \mathrm{HCl}$ and the layers separated. The aqueous layer was extracted with $\mathrm{CH}_{2} \mathrm{Cl}_{2}(2 \times 10 \mathrm{~mL})$, the organic layers were washed with sat. $\mathrm{NaHCO}_{3}(10 \mathrm{~mL}), \mathrm{H}_{2} \mathrm{O}$ $(10 \mathrm{~mL})$, dried over $\mathrm{MgSO}_{4}$ and concentrated in vacuo. The crude product was purified by column chromatography on $\mathrm{SiO}_{2}$ (hexanes/ethyl acetate $20: 1$ ) to yield colorless waxy solids.

\section{3,6,7,10,11,14,15-Heptakis[(3,4,5-dodecyl- oxybenzoyl)oxy]tetraphenylen-2-yl 3,4,5- tridodecyloxybenzoate $\mathbf{( 2 \mathbf { h } )}$}

$270 \mathrm{mg}(19 \%)$ of a colorless solid. ${ }^{1} \mathrm{H}$ NMR $(500 \mathrm{MHz}$, $\left.\mathrm{CDCl}_{3}\right): \delta=0.85-0.89(\mathrm{~m}, 72 \mathrm{H}), 1.25-1.49(\mathrm{~m}, 432 \mathrm{H})$, $1.70-1.75(\mathrm{~m}, 48 \mathrm{H}), 3.79-3.86(\mathrm{~m}, 32 \mathrm{H}), 3.98(\mathrm{t}, J=6.5 \mathrm{~Hz}$, 16H), 7.24 (s, 16H), 7.39 (s, 8H) ppm. ${ }^{13} \mathrm{C}$ NMR (125 MHz, $\left.\mathrm{CDCl}_{3}\right): \delta=14.1,22.7,26.1,26.2,29.4,29.4,29.5,29.6,29.7$, 29.7, 29.8, 29.8, 30.4, 32.0, 69.0, 73.5, 108.3, 123.0, 124.5, 138.1, 142.0, 143.0, 152.9, 163.8 ppm. FT-IR (ATR): $v=2921$ (vs), 2852 (s), 1976 (w), 1743 (m), 1585 (m), 1499 (w), 1466 (w), $1430(\mathrm{~m}), 1390(\mathrm{w}), 1335(\mathrm{~s}), 1291(\mathrm{w}), 1240(\mathrm{w}), 1190$ (s), $1114(\mathrm{~s}), 947(\mathrm{w}), 802(\mathrm{w}), 748(\mathrm{w}), 623(\mathrm{~m}), 546(\mathrm{w}) \mathrm{cm}^{-1}$. UV/VIS ( $n$-hexane): $\lambda_{\max }\left(\lg \varepsilon_{\max }\right)=275$ (5.15), 214 (5.60) nm. $\mathrm{C}_{368} \mathrm{H}_{624} \mathrm{O}_{40}$ (5688.9) calcd. C 77.69, H 11.06; found: C 77.74, H 10.95 .

\section{Supporting Information}

Supporting information includes experimental and spectroscopic data for compounds $\mathbf{2 a}-\mathbf{f}, \mathbf{2 g}-\mathbf{l}$, and X-ray diffraction measurements of derivatives $\mathbf{2} \mathbf{f}, \mathbf{j}$.

\section{Supporting Information File 1}

Analytical data of compounds $\mathbf{2 a}-\mathbf{f}, \mathbf{2 g}-\mathbf{-}$.

[http://www.beilstein-journals.org/bjoc/content/ supplementary/1860-5397-5-57-S1.pdf] 


\section{Acknowledgments}

Generous financial support by the Deutsche Forschungsgemeinschaft, the Fonds der Chemischen Industrie, the Ministerium für Wissenschaft, Forschung und Kunst des Landes Baden-Württemberg and the Bundesministerium für Bildung und Forschung (grant \# 01 RI 05177) is gratefully acknowledged.

\section{References}

1. Laschat, S.; Baro, A.; Steinke, N.; Giesselmann, F.; Hägele, C.; Scalia, G.; Judele, R.; Kapatsina, E.; Sauer, S.; Schreivogel, A.; Tosoni, M. Angew. Chem. 2007, 119, 4916-4973. doi:10.1002/ange.200604203 Angew. Chem., Int. Ed. 2007, 46, 4832-4887. doi:10.1002/anie.200604203 (Review).

2. Sergeyev, S.; Pisula, W.; Geerts, Y. H. Chem. Soc. Rev. 2007, 36, 1902-1929. doi:10.1039/b417320c (Review).

3. Tschierske, C. Annu. Rep. Prog. Chem., Sect. C: Phys. Chem. 2001, 97, 191-267. doi:10.1039/b101114f (Review).

4. Rathore, R.; Le Magueres, P.; Lindeman, S. V.; Kochi, J. K. Angew. Chem. 2000, 112, 818-821. doi:10.1002/(SICI)1521-3757(20000218)112:4<818::AID-ANGE818>3. 0.CO;2-\#

Angew. Chem., Int. Ed. 2000, 39, 809-812.

doi:10.1002/(SICI)1521-3773(20000218)39:4<809::AID-ANIE809>3.0. $\mathrm{CO} ; 2-6$

5. Iyoda, M.; Kabir, S. M. H.; Vorasingha, A.; Kuwatani, Y.; Yoshida, M. Tetrahedron Lett. 1998, 39, 5393-5396. doi:10.1016/S0040-4039(98)01082-X

6. Irngartinger, H.; Reibel, W. R. K. Acta Crystallogr., Sect. B 1981, 37, 1724-1728. doi:10.1107/S0567740881006985

7. Huang, H.; Hau, C.-K.; Law, C. C. M.; Wong, H. N. C. Org. Biomol. Chem. 2009, 7, 1249-1257. doi:10.1039/b818029f

8. Rajca, A.; Rajca, S.; Pink, M.; Miyasaka, M. Synlett 2007, 1799-1822. doi:10.1055/s-2007-984538 (Review).

9. Hou, X.-L.; Huang, H.; Wong, H. N. C. Synlett 2005, 1073-1089. doi:10.1055/s-2005-865213 (Review).

10. Mak, T. C. W.; Wong, H. N. C. In Comprehensive Supramolecular Chemistry; MacNicol, D. D.; Toda, F.; Bishop, R., Eds.; Elsevier: Oxford, U.K., 1996; Vol. 6, pp 351-369.

(Review).

11. Mak, T. C. W.; Wong, H. N. C. Top. Curr. Chem. 1987, 140, 141-164. doi:10.1007/BFb0003839 (Review).

12. Huang, H.; Stewart, T.; Gutmann, M.; Ohhara, T.; Niimura, N.; Li, Y.-X.; Wen, J.-F.; Bau, R.; Wong, H. N. C. J. Org. Chem. 2009, 74, 359-369. doi:10.1021/jo802061p

13. Wu, A.-H.; Hau, C.-K.; Wong, H. N. C. Adv. Synth. Catal. 2007, 349, 601-608. doi:10.1002/adsc.200600499

14.Peng, H.-Y.; Lam, C.-K.; Mak, T. C. W.; Cai, Z.; Ma, W.-T.; Li, Y.-X.; Wong, H. N. C. J. Am. Chem. Soc. 2005, 127, 9603-9611. doi:10.1021/ja051013।

15. Hui, C. W.; Mak, T. C. W.; Wong, H. N. C. Tetrahedron 2004, 60, 3523-3531. doi:10.1016/j.tet.2004.02.022
16. Wen, J.-F.; Hong, W.; Yuan, K.; Mak, T. C. W.; Wong, H. N. C. J. Org. Chem. 2003, 68, 8918-8931. doi:10.1021/jo0302408

17. Lai, C. W.; Lam, C. K.; Lee, H. K.; Mak, T. C. W.; Wong, H. N. C. Org. Lett. 2003, 5, 823-826. doi:10.1021/ol020253s

18. Rajca, A.; Wang, H.; Bolshov, P.; Rajca, S. Tetrahedron 2001, 57, 3725-3735. doi:10.1016/S0040-4020(01)00241-1

19. Kabir, S. M. H.; Hasegawa, M.; Kuwatani, Y.; Yoshida, M.; Matsuyama, H.; lyoda, M. J. Chem. Soc., Perkin Trans. 12001 , 159-165. doi:10.1039/b006375o

20. Kabir, S. M. H.; lyoda, M. Synthesis 2000, 1839-1842. doi:10.1055/s-2000-8239

21. Yang, X.-P.; Du, D.-M.; Li, Q.; Mak, T. C. W.; Wong, H. N. C. Chem. Commun. 1999, 1607-1608. doi:10.1039/a904144c

22. Rajca, A.; Safronov, A.; Rajca, S.; Shoemaker, R. Angew. Chem. 1997, 109, 504-507. doi:10.1002/ange.19971090510 Angew. Chem., Int. Ed. Engl. 1997, 36, 488-491. doi:10.1002/anie.199704881

23. Wang, X. M.; Hou, X.; Zhou, Z.; Mak, T. C. W.; Wong, H. N. C. J. Org. Chem. 1993, 58, 7498-7506. doi:10.1021/jo00078a031

24. Man, Y. M.; Mak, T. C. W.; Wong, H. N. C. J. Org. Chem. 1990, 55, 3214-3221. doi:10.1021/jo00297a043

25. Rashidi-Ranjbar, P.; Man, Y. M.; Sandstroem, J.; Wong, H. N. C. J. Org. Chem. 1989, 54, 4888-4892. doi:10.1021/jo00281a034

26. Wong, H. N. C.; Man, Y.-M.; Mak, T. C. W. Tetrahedron Lett. 1987, 28, 6359-6362. doi:10.1016/S0040-4039(01)91373-5

27. Wong, H. N. C.; Luh, T. Y.; Mak, T. C. W. Acta Crystallogr., Sect. C 1984, 40, 1721-1723. doi:10.1107/S0108270184009288

28. Wong, H. N. C.; Sondheimer, F. Tetrahedron 1981, 37, 99-109. doi:10.1016/0040-4020(81)85045-4

29. Wuckert, E.; Laschat, S.; Baro, A.; Hägele, C.; Giesselmann, F.; Luftmann, H. Liq. Cryst. 2006, 33, 103-107. doi:10.1080/02678290500277953

30. Wuckert, E.; Dix, M.; Laschat, S.; Baro, A.; Schulte, J. L.; Hägele, C.; Giesselmann, F. Liq. Cryst. 2004, 31, 1305-1309. doi:10.1080/02678290412331312051

31. Hägele, C.; Wuckert, E.; Laschat, S.; Giesselmann, F. ChemPhysChem 2009, 10, 1291-1298. doi:10.1002/cphc.200900090

32. Lai, C. K.; Tsai, C.-H.; Pang, Y.-S. J. Mater. Chem. 1998, 8 , 1355-1360. doi:10.1039/a800657a

33. Zheng, H.; Lai, C. K.; Swager, T. M. Chem. Mater. 1995, 7, 2067-2077. doi:10.1021/cm00059a013

34. Tinh, N. H.; Levelut, A. M.; Malthête, J. Mol. Cryst. Liq. Cryst. 1984, 106, 121-146. doi:10.1080/00268948408080183

35. Chem3D Pro 7.0 Software was used for molecular modelling. 


\section{License and Terms}

This is an Open Access article under the terms of the Creative Commons Attribution License

(http://creativecommons.org/licenses/by/2.0), which permits unrestricted use, distribution, and reproduction in any medium, provided the original work is properly cited.

The license is subject to the Beilstein Journal of Organic Chemistry terms and conditions:

(http://www.beilstein-journals.org/bjoc)

The definitive version of this article is the electronic one which can be found at:

doi:10.3762/bjoc.5.57 